\title{
Evaluation of Tunnel Contour Quality Index on the Basis of Terrestrial Laser Scanning Data
}

https://doi.org/10.2478/sgem-2021-0013

received March 26, 2021; accepted May 13, 2021.

\begin{abstract}
The Tunnel Contour Quality Index (TCI) is an index established by Kim and Bruland for an effective management of a tunnel contour quality. It is estimated on a basis of measurements of two contour profiles within a single blasting round, using a laser profiler. However, the representativeness of measurement results obtained that way for the assessment of a contour quality of the entire blasting round is disputable. Terrestrial laser scanning (TLS) technology, combined with available numerical surface modeling tools, enables development of threedimensional models of a monitored surface. The article reports results of TCI calculations based on TLS data. The presented TLS techniqueis based notonly on selected crosssections of the tunnel contour but also on the description of the morphology of the tunnel contour surface. The case study concerns measurements of the "Mały Luboń" tunnel niche, located in Naprawa, Poland. The TCI values for three blasting rounds were determined in accordance with Kim and Bruland's guidelines and were compared to TCI values determined with the proposed TLS technique. On a basis of this comparison, it can be concluded that the results obtained with the TLS technique are more reliable and representative for description of the contour quality of the entire blasting round than results obtained with the laser profiling technique.
\end{abstract}

Keywords: TCI; Tunnel; Contour quality; Terrestrial laser scanning (TLS); Overbreak; Contour roughness.

\footnotetext{
*Corresponding author: Piotr Dybet, AGH University of Science and Technology, Faculty of Mining and Geoengineering, 30-059 Cracow, al. Mickiewicza 30, Poland, E-mail: pdybel@agh.edu.pl; ORCID: 0000-0001-6602-795X

Katarzyna Dybet, AGH University of Science and Technology, Faculty of Mining Surveying and Environmental Engineering, 30-059 Cracow al. Mickiewicza 30, Poland; ORCID: 0000-0003-2213-0562 Jerzy Cieślik, AGH University of Science and Technology, Faculty of Mining and Geoengineering, 30-059 Cracow, al. Mickiewicza 30, Poland; ORCID: 0000-0001-9993-2454
}

\section{Highlights}

- Terrestrial laser scanning can be successfully used for TCI evaluations.

- TLS technique for TCI evaluation is proposed.

- TLS was measured in a tunnel bored in the Carpathian flysch.

- Triangulated Irregular Network was used to model the contour surface.

- The $\mathrm{O}_{\mathrm{d}}$ and RCL values for the sides and the roof were compared.

\section{Acronyms and Symbols}

TCI, Tunnel Contour Quality Index

TLS, terrestrial laser scanning

RMR, rock mass rating

JRC, joint roughness coefficient

TIN, Triangulated Irregular Network

NURBS, non-uniform rational B-spline

GRID, interpolation of values in mesh nodes

$\mathrm{D} \& \mathrm{~B}$, drill and blast

\section{Introduction}

Tunnel Contour Quality Index (TCI) is an index proposed by Kim and Bruland [1]. It is a numerical measure of the quality of a tunnel contour and was established for the effective management of a tunnel contour quality. It is intended to help tunnel engineers in comparisons of the contour quality for different tunnels or for different sections of one tunnel and in assessing the influence of various factors on the tunnel contour quality. Kim and Bruland [1] found a relationship between the TCI value and geological and operational conditions in drill and blast (D\&B) tunnels. In general, the TCI value is a function of three parameters: the overbreak depth $\left(\mathrm{O}_{\mathrm{d}}\right)$, the contour roughness (RCL), and the longitudinal overbreak variation $\left(\mathrm{V}_{\mathrm{o}}\right)$ (Fig. 1). The TCI may be calculated for a single blasting 

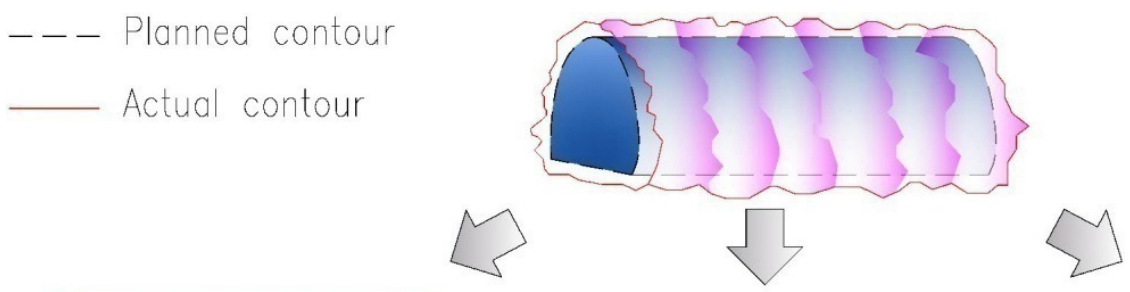

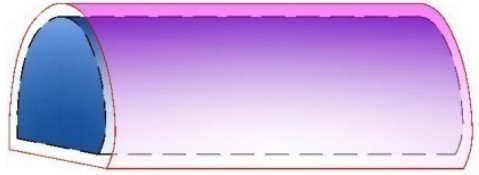

Overbreak depth $\left(\mathrm{O}_{\mathrm{d}}\right)$

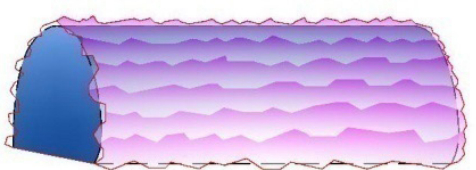

Contour roughness (RCL)

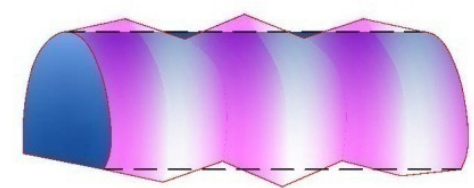

Longitudinal overbreak variation $\left(V_{0}\right)$

Figure 1: Three elements characterizing a contour quality [1].

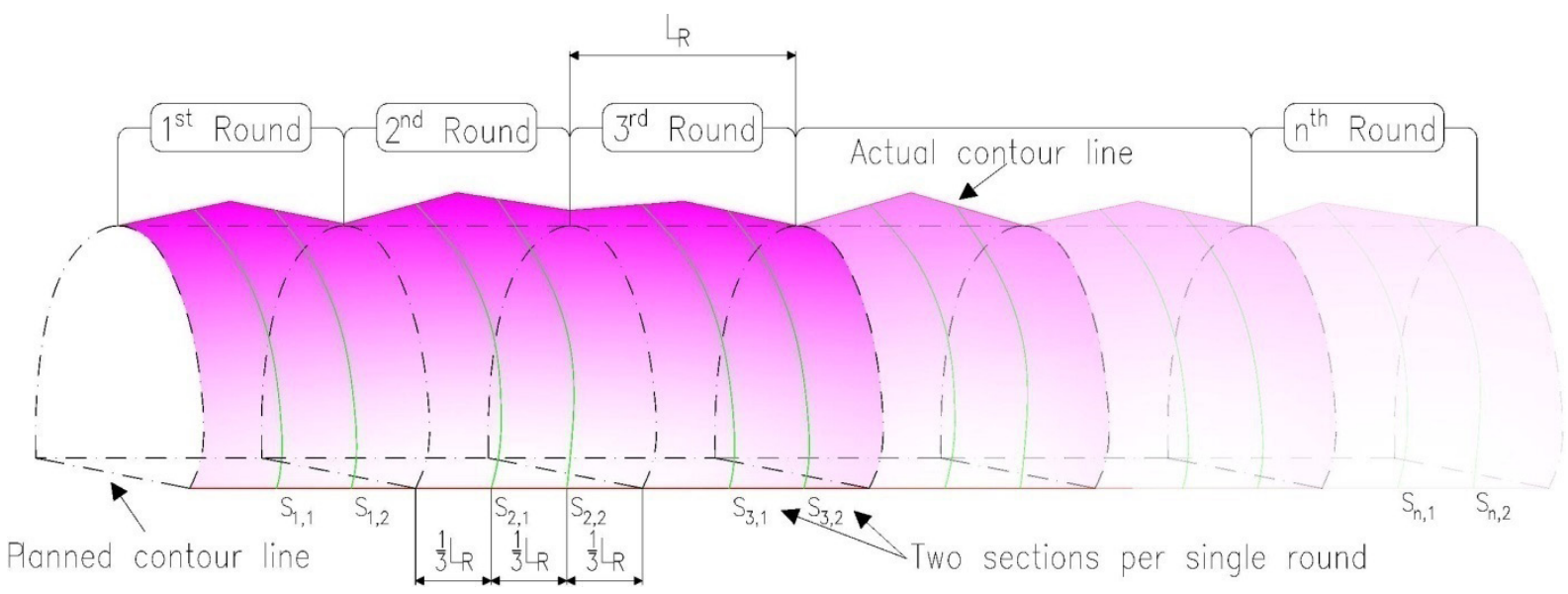

Figure 2: Spacing of measurement sections within a single blasting round [1].

round $\left(\mathrm{TCI}_{\mathrm{R}}\right)$ or for an entire tunnel (more than five blasting rounds) $\left(\mathrm{TCI}_{\mathrm{T}}\right)$.

Values of the $\mathrm{O}_{\mathrm{d}}$, RCL, and $\mathrm{V}_{\mathrm{o}}$ parameters are calculated using the laser profiling technique. Within a single blasting round, the tunnel contour is measured in two cross-sections, i.e., at one third and two thirds of its length $\left(\mathrm{L}_{\mathrm{R}}\right)$. Spacing of the measurement crosssections within a single blasting round is shown in Fig. 2. With regard to the measurement methodology described in [1], it was proposed that the distance between successive measurement points on the contour profile (i.e., a measurement interval) should correspond to an approximately half of a normal drilling spacing for contour holes. The measurement methodology adjusted in this way limits to some extent the capability for accurate modeling of the measured profile. This capability is correlated with the number of measurement points along the length of the contour profile, assuming that their distribution over this length is as even as possible. With the laser profiling technique, cross-sections of the tunnel contour can be measured with a laser profiler. At the same time, Kim and Bruland [1] mentioned that there are more effective and accurate measuring methods available, such as terrestrial laser scanning (TLS), but the majority of tunneling sites still uses traditional measuring instruments, such as a laser profiler. Costamagna et al. [2] emphasize the possibility of using a wide range of geodetic instruments (e.g., a theodolite, a total station, and photogrammetry) to obtain geometric data during the tunneling process.

Terrestrial laser scanning (TLS) technology is currently gaining increasing interest [3]. It is successfully used for control and diagnostic measurements of various building structures [4-6]. The advantage of this technology is a possibility of contactless acquisition of a large amount of information about a given object, i.e., point clouds, in a relatively short time. TLS enables measurements with an accuracy of several millimeters [4]. However, the scanning accuracy does not depend solely on the instrument, but 
also on a number of different factors. One of them is the specificity of the surface of a measured object [7]. Moistened surfaces or surfaces inclined at a large angle to the scanner may hinder accurate measurements and limit its measuring range [8]. Further examples of factors influencing the measurement accuracy of TLS include temperature, pressure, humidity, and airborne dust [9]. TLS represents a valuable alternative or a supplement to classic geodetic measurements [10]. With appropriate numerical surface modeling tools (e.g., TIN, GRID, and NURBS), reliable models of the measured surface $[5,11,12]$ can be created on the basis of the measured point cloud. The development of TLS technology, together with the increase in the measurement speed and accuracy, means that options for using this technology in complex field conditions are expanding.

So far, a lot of research has focused on the possible application of the TLS technology in tunneling. [13] is an example of an article summarizing and systematizing the achievements in this field. TLS is used to measure the displacement of the contour points of the tunnel initial and final lining $[14,15]$. Cheng et al. [16] and Han et al. [17] attempted to automate the process of the tunnel lining modeling on the basis of the measured point cloud. Some research was also conducted to confirm a possibility of using TLS for tunnel inspections, including crack [18] and moisture [19] detection on the tunnel lining. The usefulness of TLS technology in determining the type of rock and a content of moisture fractions in the rock mass was demonstrated in [20]. At the same time, continuous attempts are made to improve the TLS measurement procedures in the tunnel, to ensure that they are as accurate as possible [21].

The aim of this article was to determine the possibility of using theTLS data in the TCI evaluation. For this purpose, modification in the TCI calculation methodology was proposed. It takes into account the use of TLS technology in combination with the available numerical surface modeling tool - TIN. This way, a three-dimensional model of the monitored surface can be created. Contrary to the laser profiling technique, the TLS technique for the TCI evaluation is based not only on selected tunnel contour profiles but also on a description of the tunnel contour surface morphology. The proposed modification opens a possibility for determining the precise relationships between the TCI value and various factors influencing it, e.g., geological conditions or a distribution and type of explosives used. When these relationships are established, it will be possible to determine TCI usefulness.

\section{Data collection and methodology}

The TLS measurements of the tunnel contour surface were performed in one of the niches of the "Mały Luboń" tunnel along the S7 expressway (section II Lubień-Rabka, km 723 $+800)$ in Naprawa, Poland. The niche was drilled in the Carpathian flysch formed mainly by sandstone layers [22]. The tunnel was bored using the ADECO RS method, with explosives (D\&B tunneling). For the discussed niche, the designed blasting round length was 3 meters. Figure 3 shows a cross-section and drill patterns for the studied niche. $1.9 \mathrm{~kg}$ of explosives per $1 \mathrm{~m}^{3}$ of excavated material was used during the blasting works.

The tunnel contour surface was measured with the FARO Focus 3D S150 scanner (Fig. 4a) after completion of the blasting works. The parameters of scanner and scanning process are presented in Table 1 [23]. TLS measurements of linear objects such as a tunnel are characterized by a variable density of measured points along the length of that object. The farther the measured surface is from the scanner, the less dense the cloud of measured points is. Therefore, when performing scanning measurements in a tunnel, it is necessary to adjust the appropriate location and the number of scanner stations. For the niche in question, due to its small size (crosssection area: $\sim 21.30 \mathrm{~m}^{2}$, length: $\sim 9.0 \mathrm{~m}$ ), it was decided to perform measurements from one measurement station, centrally located inside the studied object (Fig. 4b).

Before starting the tunnel contour surface measurements, values of the scanning process parameter were adjusted (Table 1). For this purpose, one of the available measurement profiles was selected. Each profile has automatically defined basic scanning settings, including measurement range, resolution, quality, scanning angles, scanning time, scan size, photo options, use of additional compensators, etc. The entire measured surface was free of any accumulated moisture. No significant quantities of airborne dust were found (the niche in question was located near one of the tunnel portals, which ensured its ventilation). The scanner used for measurements is equipped with built-in temperature and air pressure sensors, and it automatically takes into account the influence of these factors on the measurement.

The data were processed using the SCENE 2019 [24] and Autodesk ReCap 2015 [25] software. For the subsequent blasting round, data collected for each 3.0-m-long round were used for the analyses (Fig. 5). Each blasting round was divided into four parts: roof, side 1 , side 2 , and floor. Similar to [1], points corresponding to the tunnel floor were not taken into account in the analyses. 

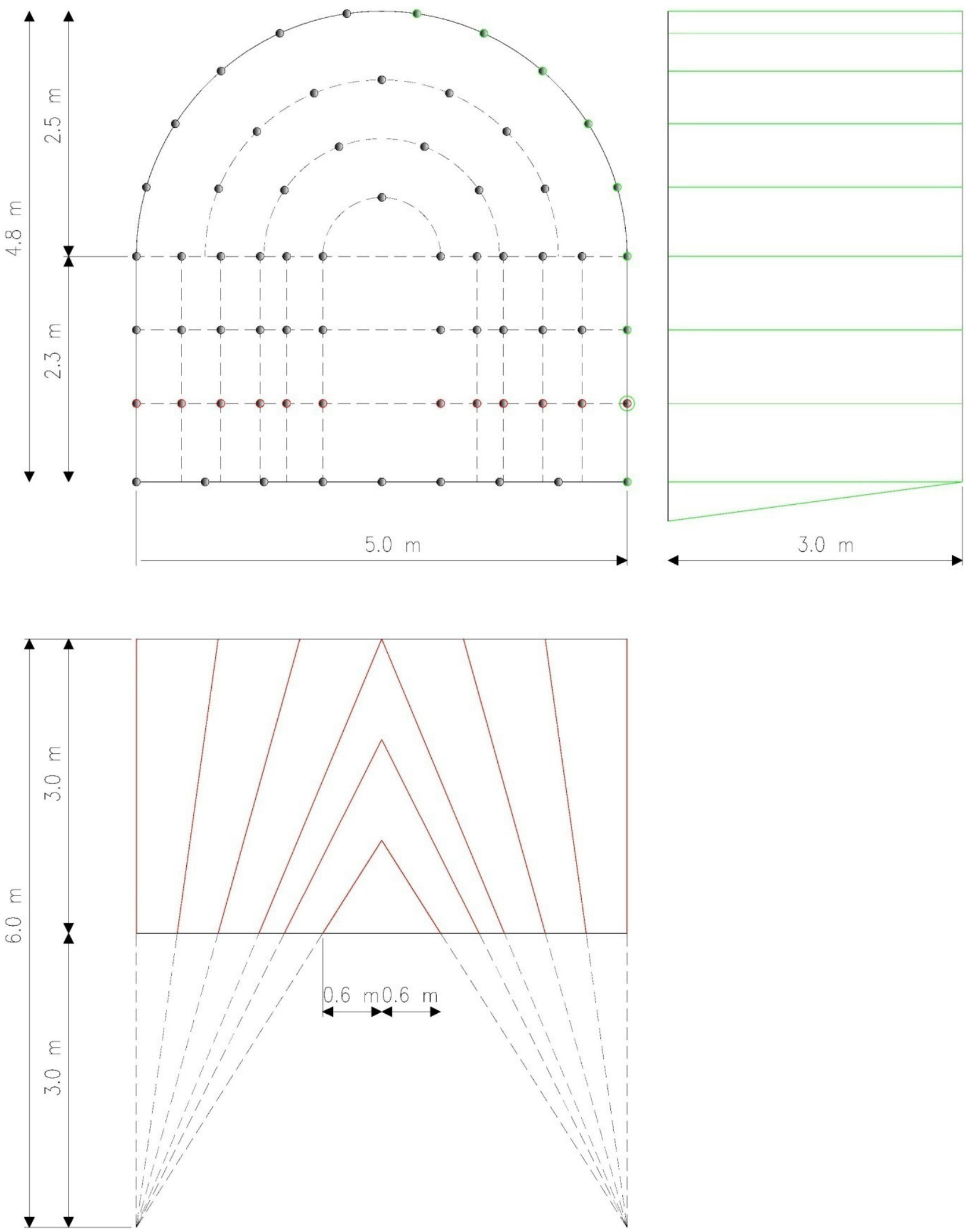

Figure 3: A cross-section and a drill pattern for the studied niche. 
Table 1: Parameters of the FARO Focus 3D S150 scanner and scanning process [23].

\begin{tabular}{ll}
\hline Parameter & Value \\
\hline Range & $0,6 \mathrm{~m}$ do $150 \mathrm{~m}$ \\
Precision & $+/-1 \mathrm{~mm}$ \\
Measurement speed & Up to 976,000 points $/ \mathrm{s}$ \\
Laser & Class 1 \\
Weight & $4.2 \mathrm{~kg}$ \\
Size & $230 \times 183 \times 103 \mathrm{~mm}$ \\
Control & Touch display and WLAN \\
Extra & Global Positioning System (GPS), \\
& compass, altimeter, two-axis \\
compensator \\
Measurement range & Indoor up to $10 \mathrm{~m}$ \\
Resolution [MPts] & $28.0(1 / 5)$ \\
Quality & $4 \times$ \\
Horizontally & $0^{\circ}$ do $360^{\circ}$ \\
Perpendicularly & $-60^{\circ}$ do $90^{\circ}$ \\
Scanning time [mm:ss] & $05: 28$ \\
Scan size [Pts] & $8192 \times 3413$ \\
\hline
\end{tabular}

Data for roof and side points collected with a laser scanner were used to build a spatial model of the tunnel (Fig. 5) using the AutoCAD Civil 3D 2015 [26] software. Parameters such as surface type, name, and display method were defined in the program. To ensure the accuracy of mapping of high-resolution scanning data, a Triangulated Irregular Network (TIN) surface, i.e., a surface formed by a triangular mesh, was used. The mesh was generated using the Delaunay triangulation. The models of side 1 and roof surfaces for the $2^{\text {nd }}$ blasting round are presented in Figure 6.

\section{Methodology of the TCI evaluation}

\subsection{Methodology of the $\mathrm{TCl}$ evaluation based on a laser profiling technique}

The formula for the $\mathrm{TCI}_{\mathrm{T}}$ evaluation, i.e., calculated for the entire tunnel or more than five blasting rounds, proposed by Kim and Bruland [1], is as follows:
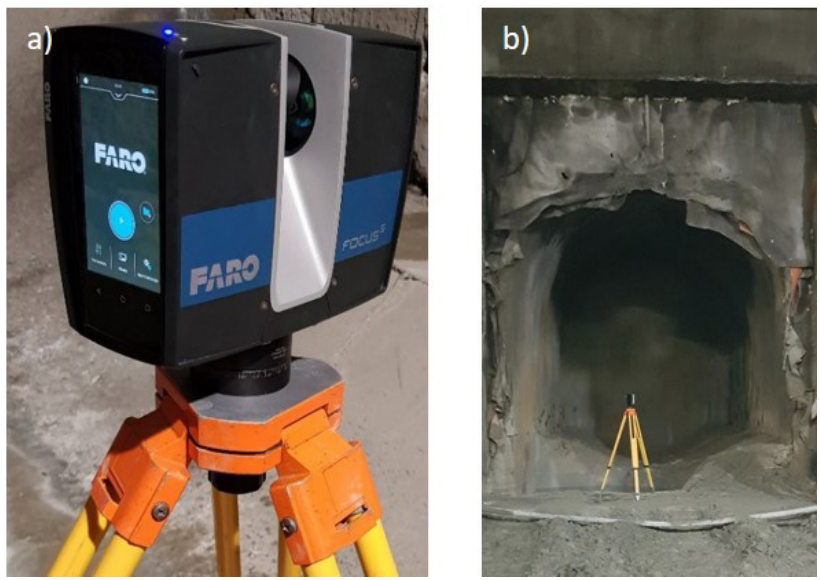

Figure 4: (a) Scanner FARO Focus 3D S150. (b) Location of the measuring station.

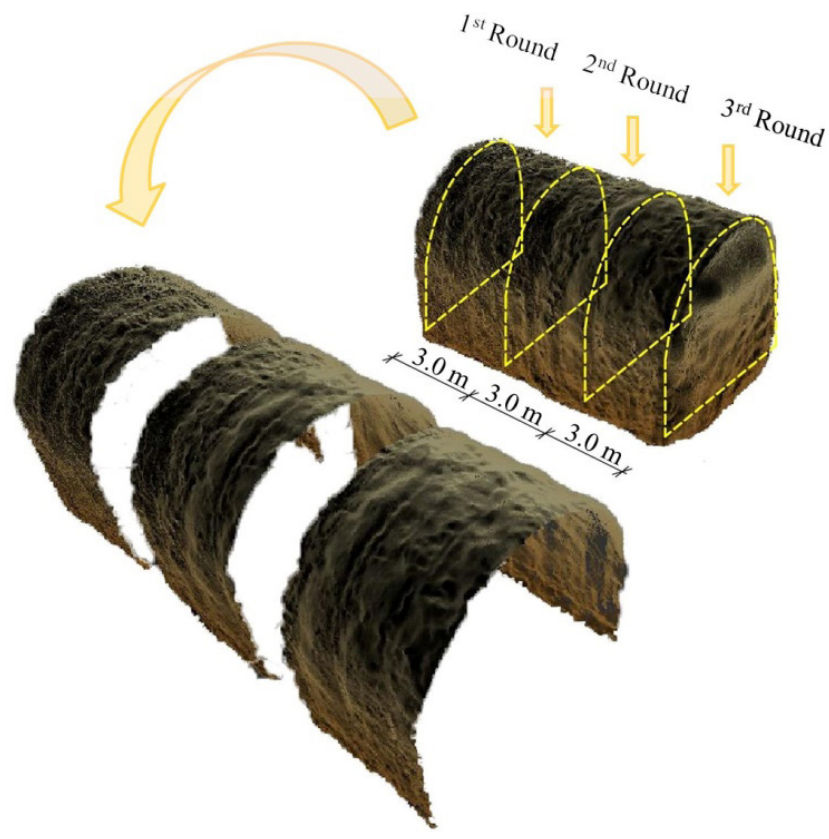

Figure 5: Division of the acquired point cloud.

$$
T C I_{T}=\frac{C_{r}}{W_{1} C_{1} \overline{O_{d}}+W_{2} C_{2} \overline{R C L}+W_{3} C_{3} V_{o}}
$$

where the values of $\overline{O_{d}}$ and $\overline{R C L}$ are the arithmetic means of the parameters $O_{d}$ and $R C L$, respectively, calculated for all measured contour profiles of the tunnel or more than five blasting rounds. Two contour profiles were measured within a single blasting round, at one third and two thirds of its length $\left(L_{R}\right) . C_{r}$ is a dimensionless constant for the range adjustment and its value is equal to $300 . W_{1}, W_{2}$, and $W_{3}$ are the weights of the parameters $O_{d}, R C L$, and 
a)
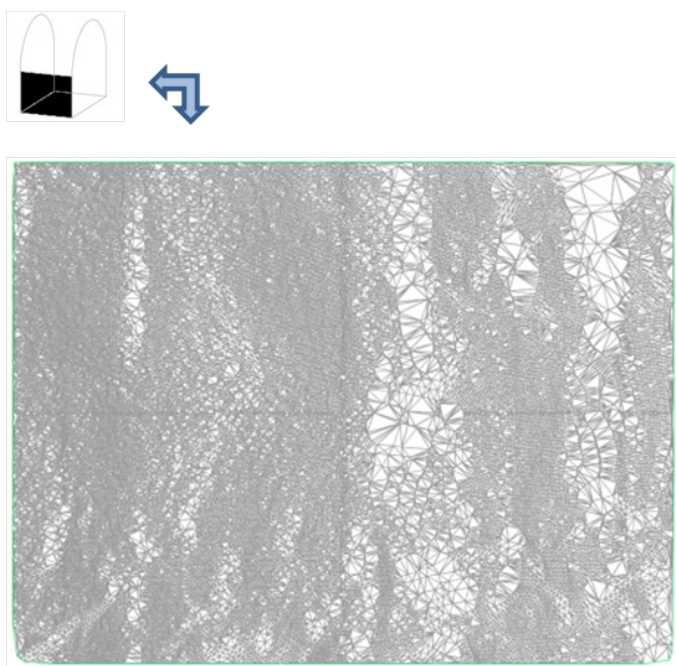

b)
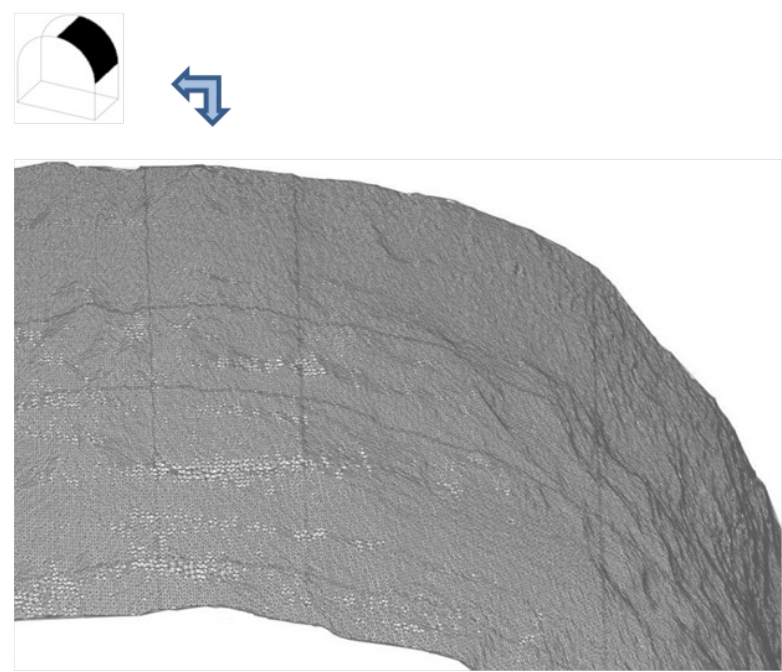

Figure 6: Side 1 (a) and roof (b) models for the $2^{\text {nd }}$ blasting round created in AutoCAD Civil 3D.

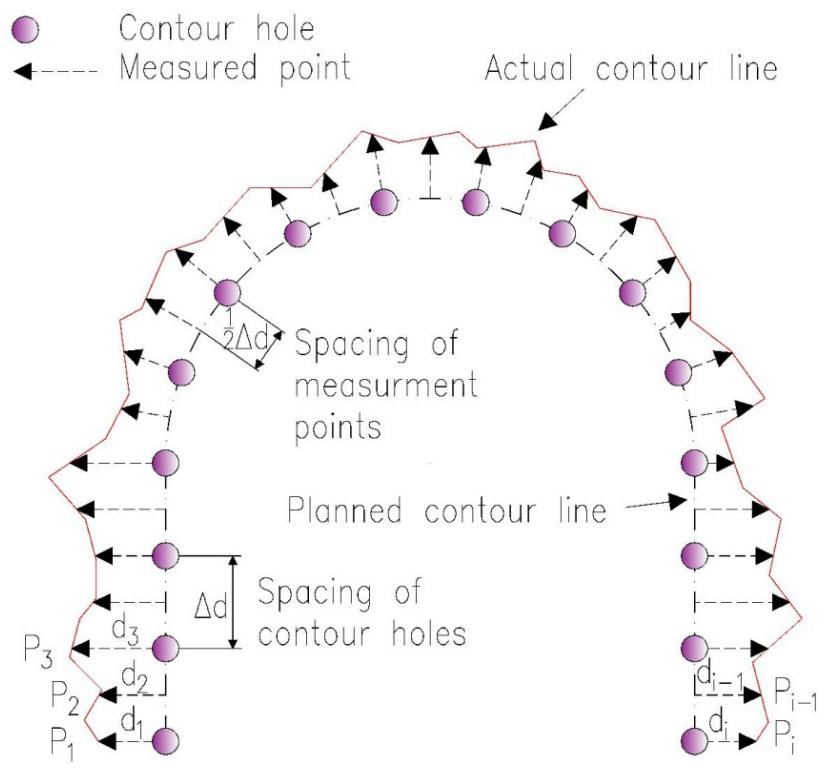

Figure 7: Measurement points arrangement on the planned contour profile.

$V_{o}$, respectively. Their values correspond to importance of several parameters for the contour quality, and according to [1], they are equal to 4.5, 4.5, and 1.0, respectively. $C_{1}, C_{2}$, and $C_{3}$ are correction factors derived from the distribution of $O_{d}, R C L$, and $V_{o}$ for all blasting rounds surveyed in [1], and they are suggested to be $0.008,0.8$, and 0.02 , respectively. For a single measured contour profile, the value of the overbreak depth $\left(O_{d}\right)$ is calculated according to the formula:

$$
O_{d}=\frac{1}{N} \sum_{i=1}^{N}\left|d_{i}\right|
$$

where $d_{i}$ is the distance of the $\mathrm{i}$-th measurement point from the planned contour line (Fig. 7). In [1], the distance between successive measurement points on the planned contour profile (i.e., measurement interval) corresponds to approximately half of the normal drilling spacing for contour holes. Thus, overbreak depth $\left(O_{d}\right)$ is defined as an average distance of the measurement points from the planned contour.

The contour roughness value $(R C L)$ for a single section is given by the formula:

$$
R C L=\frac{L_{a}}{L_{p}}
$$

where $L_{a}$ and $L_{p}$ denote the lengths of the modeled and planned contour lines, respectively (Fig. 8). The $L_{a}$ value should be calculated using the formula:

$$
L_{a}=\sum_{i=1}^{N} \sqrt{\left(X_{i}-X_{i-1}\right)^{2}+\left(Y_{i}-Y_{i-1}\right)^{2}}
$$

where $X_{i}, Y_{i}$ are the coordinates of a single measurement point. Thus, it is a sum of lengths of all sections between successive measurement points. 


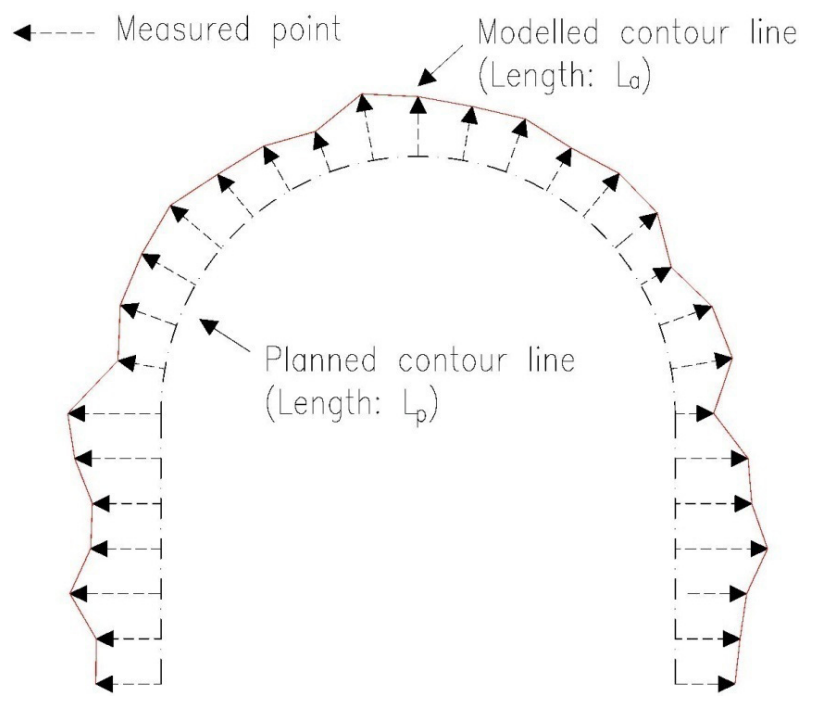

Figure 8: Modeled and planned contour lines.
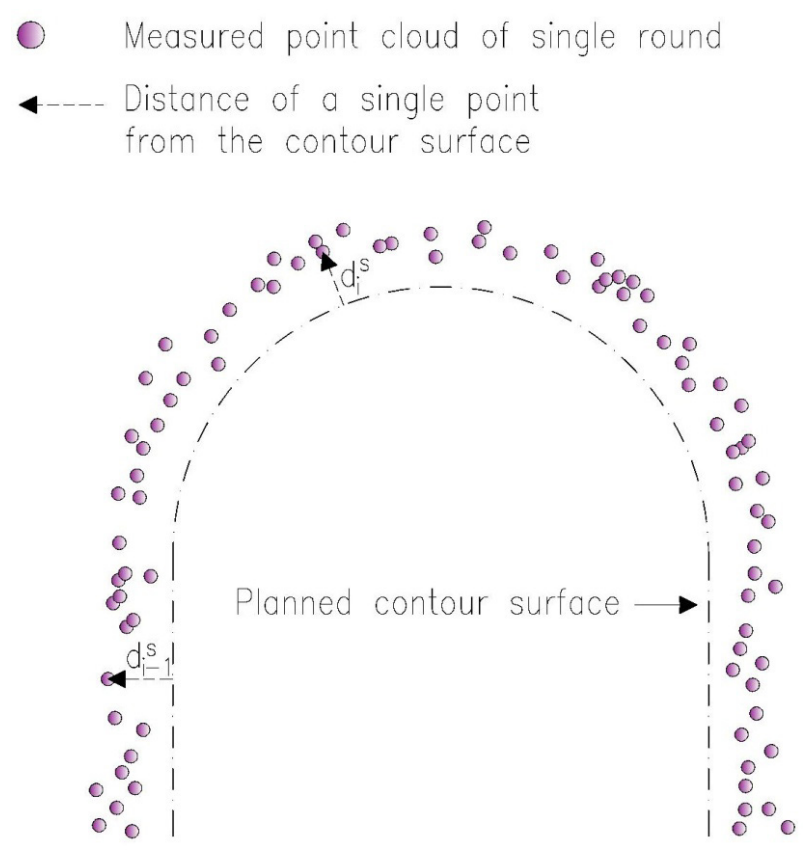

Figure 9: Tunnel cross-section view of the measured point cloud.

The value of the longitudinal overbreak variation $\left(V_{o}\right)$ is calculated using the formula:

$$
V_{o}=\frac{1}{N} \sum_{i=1}^{N}\left|o_{d_{i-1}}-O_{d_{i}}\right|
$$

where $O_{d_{i}}$ means the overbreak depth $O_{d}$ calculated for the $i$-th measured contour profile. Thus, it is an arithmetic mean of all differences in the overbreak depth $O_{d}$ calculated for the successive measured contour profiles.
In turn, the formula for the $\mathrm{TCI}_{\mathrm{R}}$ value, i.e., calculated for a single blasting round, has the following form:

$$
T C I_{R}=\frac{C_{r}}{W_{1} C_{1} \overline{O_{d}}+W_{2} C_{2} \overline{R C L}}
$$

where $\overline{O_{d}}$ and $\overline{R C L}$ denote the values of the overbreak depth $\left(O_{d}\right)$ and the contour roughness $(R C L)$, respectively, averaged for the two measured contour profiles. The maximum value of the TCI $\left(\mathrm{TCI}_{\mathrm{T}}\right.$ or $\left.\mathrm{TCI}_{\mathrm{R}}\right)$ is 83.(3) and corresponds to the highest quality of the contour. It is achieved when the parameters $\overline{O_{d}}, \overline{R C L}$, and $V_{o}$ equal $0 \mathrm{~cm}$, 1 , and $0 \mathrm{~cm}$, respectively, and therefore, the actual contour profile is the same as a planned contour profile.

\subsection{Modification of the $\mathrm{TCl}$ evaluation methodology for the TLS data}

The methodology of determining the Tunnel Contour Quality Index (TCI) based on data from the terrestrial laser scanning (TLS) is generally based on formulas (1) and (6), but includes some modifications. It takes into account the redefined parameters of the overbreak depth $\left(\overline{O_{d}} \rightarrow \overline{O_{d}^{s}}\right)$, the contour roughness $\overline{\left(R C L \rightarrow R C L^{s}\right)}$, and the longitudinal overbreak variation $\left(V_{o} \rightarrow V_{o}^{s}\right)$, to adapt them to the effective use of TLS data. The values of the constant $\left(C_{\mathrm{r}}\right)$, the weights $\left(\mathrm{W}_{1}, \mathrm{~W}_{2}\right.$, and $\left.\mathrm{W}_{3}\right)$, and the correction factors $\left(\mathrm{C}_{1}, \mathrm{C}_{2}\right.$, and $\mathrm{C}_{3}$ ) remain unchanged and are consequently applied throughout this paper. $T C I_{T}$ and $T C I_{R}$ calculated according to the TLS technique are proposed to be marked as $T C I_{s}{ }^{T}$ and $T C I^{s}$, respectively. According to the TLS technique:

1. $\overline{O_{d}^{s}}$ is the overbreak depth defined as an arithmetic mean value for a distance between all measurement points of the resultant point cloud (Fig. 9) and the planned contour surface (7). When $T C I_{T}^{s}$ is calculated, this cloud contains points measured over the entire length of the tunnel, or more than five blasting rounds; while for calculating $T C I^{s}$, the point cloud includes points measured within a single blasting round.

$$
\overline{O_{d}^{s}}=\frac{1}{N} \sum_{i=1}^{N}\left|d_{i}^{s}\right|
$$

2. $\overline{\left.R C L^{s}\right)}$ is a contour roughness defined as a value of a ratio of an area of the modeled contour surface $\left(A_{a}\right)$ 


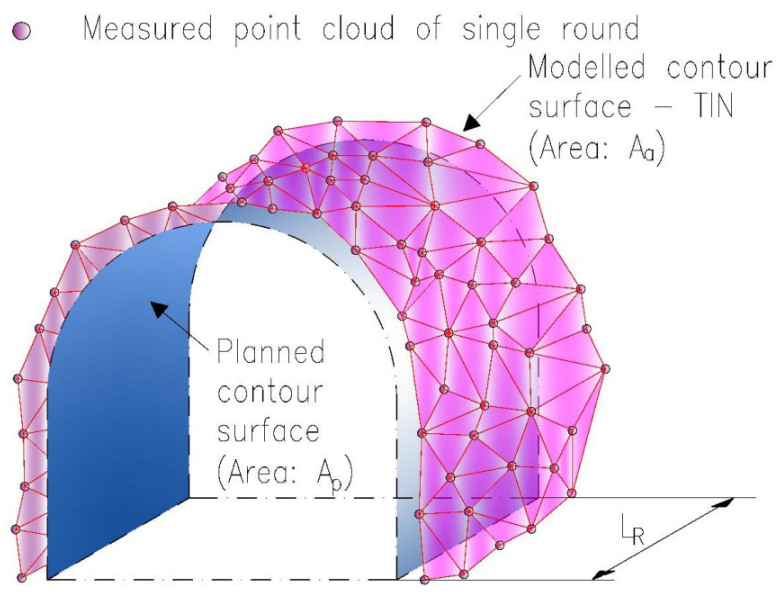

Figure 10: Modeled tunnel contour surface determined for a single blasting round.

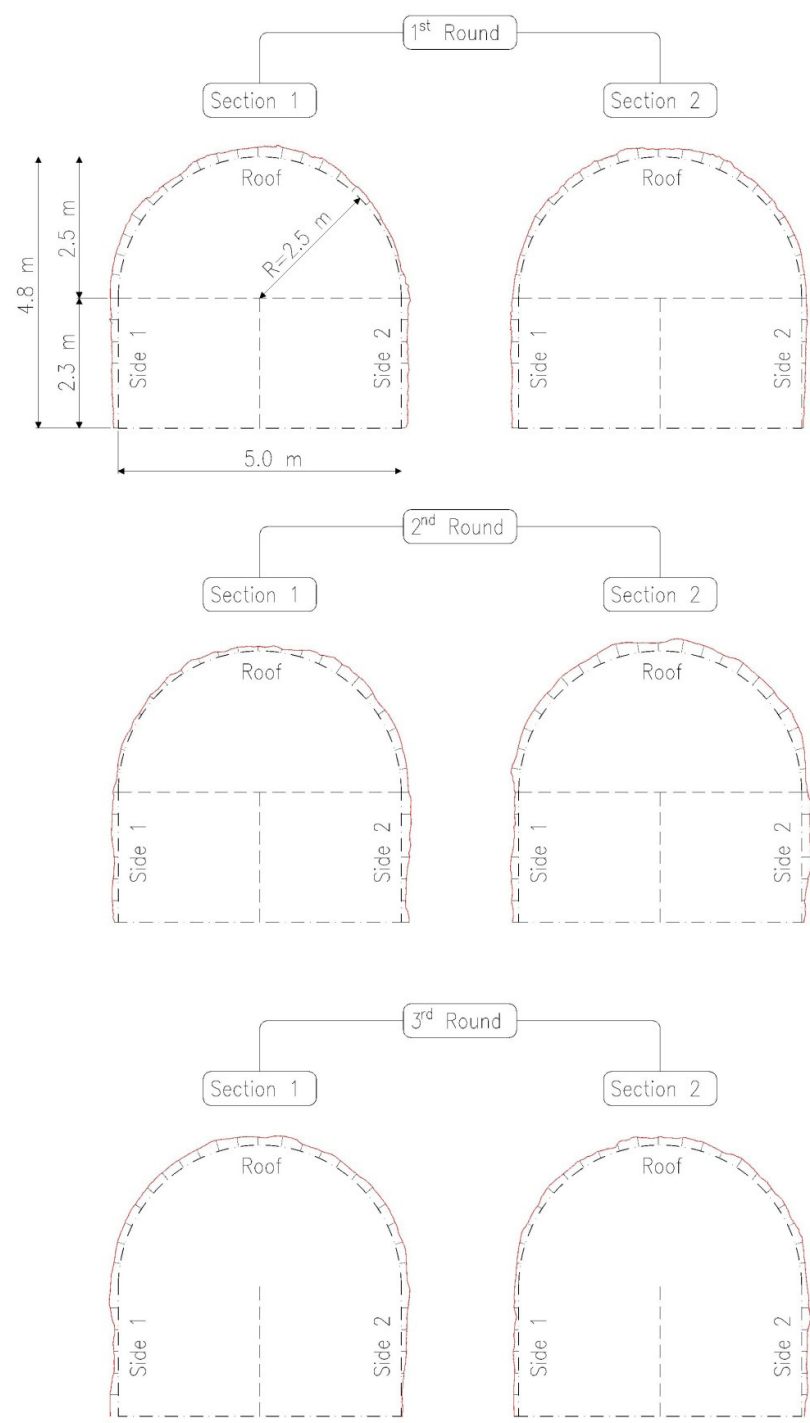

Figure 11: Cross-sections 1 and 2 for each of the three blasting rounds, obtained on the basis of the TIN surface.
(Fig. 10) to an area of the planned contour surface $\left(A_{p}\right)$ (8). When $T C I_{T}^{s}$ is calculated, the modeled contour surface is created on the basis of a point cloud measured over the entire length of the tunnel (or more than five blasting rounds). For calculating $T C I^{s}$, the modeled contour surface is created on the basis of a point cloud measured within a single blasting round. Similarly, the values of $A_{p}$ should be related to the length of the entire tunnel (or more than five blasting rounds) (for $T C I_{T}^{s}$ ) and to the length of a single blasting round (for $T C I_{R}^{s}$ ).

$$
\overline{R C L^{s}}=\frac{A_{a}}{A_{p}}
$$

3. $V_{o}^{\mathrm{s}}$ is a longitudinal overbreak variation defined as an arithmetic mean for all absolute values of the overbreak depth $\left(\overline{O_{d}^{s}}\right)$ differences calculated between the successive measurement sections (9). It is proposed that the length of a single measurement section should be half the length of the blasting round, i.e., $0.5 \mathrm{~L}_{\mathrm{R}}$. The overbreak depth $\left(\overline{O_{d, i}^{s}}\right)$ value for a single measurement section is calculated in the same way as in point 1 .

$$
V_{o}^{S}=\frac{1}{N} \sum_{i=1}^{N}\left|\overline{O_{d, i-1}^{s}}-\overline{O_{d, i}^{s}}\right|
$$

\section{$4 \mathrm{TCl}$ evaluation results}

\subsection{TCI results for laser profiling technique}

All data used in the analyses were collected with a terrestrial laser scanner. Thus, for each analyzed cross-section, contour profiles for the laser profiling technique were obtained on the basis of the created TIN surface. For this purpose, the AutoCAD Civil 3D 2015 was used. As a result, six polylines were obtained, constituting cross-sections 1 and 2 of each of the three blasting rounds (Fig. 11).

For the studied niche, the normal drilling spacing for contour holes was approximately $70-80 \mathrm{~cm}$ (Fig. 3). Therefore, in accordance with [1], $35 \mathrm{~cm}$ was adopted as a measurement interval. This gives 35 measuring points evenly distributed on the planned contour profile. Taking into account the formulas $(2-4,6)$ and on the basis of the six previously prepared sections, the parameters of the overbreak depth $\left(\mathrm{O}_{\mathrm{d}}\right)$ and the contour roughness (RCL) were calculated for the side 1, side 2, the roof, and, 
Table 2: Summary of the results obtained by the laser profiling technique (according to [1]).

\begin{tabular}{|c|c|c|c|c|c|}
\hline \multirow[t]{2}{*}{ Round } & \multirow[t]{2}{*}{ Element } & \multirow[t]{2}{*}{ Cross-section } & \multicolumn{2}{|l|}{ Parameter } & \multirow[t]{2}{*}{$T C I_{R}$} \\
\hline & & & Overbreak depth $\left(O_{f}\right)[\mathrm{cm}]$ & Contour roughness $(R C L)[-]$ & \\
\hline \multirow[t]{8}{*}{ Round 1} & Side 1 & 1 & 11.661 & 1.001 & \multirow[t]{8}{*}{71.657} \\
\hline & & 2 & 12.379 & 1.001 & \\
\hline & Side 2 & 1 & 11.102 & 1.003 & \\
\hline & & 2 & 6.389 & 1.001 & \\
\hline & Roof & 1 & 14.232 & 1.060 & \\
\hline & & 2 & 13.906 & 1.055 & \\
\hline & Entire round & 1 & 13.092 & 1.039 & \\
\hline & & 2 & 12.097 & 1.035 & \\
\hline \multirow[t]{8}{*}{ Round 2} & Side 1 & 1 & 9.612 & 1.004 & \multirow[t]{8}{*}{71.343} \\
\hline & & 2 & 9.825 & 1.002 & \\
\hline & Side 2 & 1 & 12.813 & 1.004 & \\
\hline & & 2 & 12.162 & 1.004 & \\
\hline & Roof & 1 & 10.930 & 1.045 & \\
\hline & & 2 & 17.387 & 1.073 & \\
\hline & Entire round & 1 & 11.046 & 1.030 & \\
\hline & & 2 & 14.764 & 1.048 & \\
\hline \multirow[t]{8}{*}{ Round 3} & Side 1 & 1 & 11.241 & 1.006 & \multirow[t]{8}{*}{72.190} \\
\hline & & 2 & 7.84 & 1.001 & \\
\hline & Side 2 & 1 & 7.430 & 1.002 & \\
\hline & & 2 & 9.593 & 1.002 & \\
\hline & Roof & 1 & 14.458 & 1.058 & \\
\hline & & 2 & 12.796 & 1.052 & \\
\hline & Entire round & 1 & 12.409 & 1.039 & \\
\hline & & 2 & 11.164 & 1.034 & \\
\hline
\end{tabular}

finally, the entire blasting round. The obtained results are summarized in Table 2.

The obtained results can be considered representative only for that short length of the niche that is in close proximity to the measured contour profiles. In addition, the small number of 35 measuring points evenly distributed along the planned contour profile does not allow for an accurate modeling of the actual profile line. Thus, these results only provide some approximation of the actual contour quality. The authors of this paper propose the TLS technique as an alternative to the laser profiling technique for the TCI evaluation proposed in [1], because it enables an efficient use of large amounts of TLS data. The starting point for determining the TLS technique is the statement that the possibility of accurate modeling of the tunnel contour surface increases with the number of measured points (provided, however, that all points are distributed on the surface as evenly as possible).

\section{2 $\mathrm{TCl}$ results for TLS technique}

Table 3 presents the values of $\overline{O_{d}^{s}}$ and $\overline{R C L^{s}}$ calculated in accordance with the TLS technique for individual elements (i.e., side 1 , side 2 , and roof) of each of the three blasting rounds for the studied niche. The areas of the modeled contour surfaces $\left(A_{a}\right)$ of side 1 , side 2 , and roof were read from AutoCAD Civil 3D.The area of the planned contour surface $\left(A_{p}\right)$ is $6.9 \mathrm{~m}^{2}$ for each of the sides, and $23.56 \mathrm{~m}^{2}$ for the roof. 
Table 3: Summary of the results obtained by the TLS technique.

\begin{tabular}{|c|c|c|c|c|}
\hline \multirow[t]{2}{*}{ Round } & \multirow[t]{2}{*}{ Element } & \multicolumn{2}{|l|}{ Parameter } & \multirow[t]{2}{*}{$T C l^{s}$} \\
\hline & & Overbreak depth $\overline{O_{d}^{s}}[\mathrm{~cm}]$ & $\begin{array}{l}\text { Contour roughness } \overline{R_{C L^{s}}} \\
{[-]}\end{array}$ & \\
\hline \multirow[t]{4}{*}{ Round 1} & Side 1 & 8.624 & 1.116 & 64.232 \\
\hline & Side 2 & 10.893 & 1.155 & \\
\hline & Roof & 14.111 & 1.192 & \\
\hline & Entire round & 12.640 & 1.171 & \\
\hline \multirow[t]{4}{*}{ Round 2} & Side 1 & 9.146 & 1.042 & 67.943 \\
\hline & Side 2 & 11.149 & 1.069 & \\
\hline & Roof & 12.416 & 1.140 & \\
\hline & Entire round & 11.737 & 1.109 & \\
\hline \multirow[t]{4}{*}{ Round 3} & Side 1 & 12.094 & 1.055 & 68.578 \\
\hline & Side 2 & 6.695 & 1.072 & \\
\hline & Roof & 12.335 & 1.123 & \\
\hline & Entire round & 11.350 & 1.102 & \\
\hline
\end{tabular}

\section{Analysis and discussion}

\subsection{Contour quality of individual blasting rounds for laser profiling and TLS techniques}

Out of the three studied blasting rounds, round 3 has the highest quality of the contour, regardless of the technique used. This is due to the fact that the calculated values of the overbreak depth and the contour roughness are the lowest out of all three blasting rounds. For the laser profiling technique, they are $\overline{O_{d}}=11.787$ and $\overline{R C L}=1.037$, respectively. For the TLS technique, these values are $\overline{O_{d}^{s}}=$ $11.350 \mathrm{~cm}$ and $\overline{R C L^{s}}=1.102$, respectively. Round 2 shows the poorest quality of the contour determined on the basis of the measured contour profiles $\left(T C I_{R}=71.343\right)$. It is also characterized by the greatest overbreak depth of all blasting rounds $\left(\mathrm{O}_{d}=12.905 \mathrm{~cm}\right)$. On the other hand, round 1 has the lowest value of $T C I^{R}=64.232$. It is characterized by the highest value of the contour roughness among all blasting rounds, of $\overline{R C L^{s}}=1.171$. The difference between the highest and the lowest $T C I_{R}$ value calculated with the laser profiling technique amounts approximately to $\triangle T C I_{R}$ $=0.847$. In the case of TLS technique, a similar difference is $\Delta T_{C I}{ }^{R}=4.346$. The quotient of each of these values and the appropriate lowest value of the $T C I_{R}\left(\Delta T C I_{s}^{R}\right)$ is $0.047 / 71.343$ $=0.012$ and 4.346/64.232 $=0.068$, respectively. This means that the contour quality of individual blasting rounds is more diversified when we take into account the results obtained with the TLS technique for TCI calculation.

\subsection{Differences in results obtained with laser profiling and TLS techniques and their causes}

In the studied niche, the average value of the $T C I_{s}{ }^{R}$ for three blasting rounds, calculated using the TLS technique, is 66.918. Therefore, it is approximately $6.7 \%$ lower than the value calculated using the laser profiling technique. The discrepancies in the results are caused by differences in the values of the overbreak depth and the contour roughness parameters calculated for the two techniques. The average value of the overbreak depth ( $\overline{O_{d}}$ for three blasting rounds, calculated in accordance with [1], is $12.429 \mathrm{~cm}$. However, when determined with the TLS technique, it is approximately $4.2 \%$ lower ( $\overline{O_{d}^{s}}=11.909 \mathrm{~cm}$ ). For the average value of the contour roughness, the relationship is opposite. In this case, using the TLS technique, $\overline{R C L^{s}}=1.127$ and is approximately $8.6 \%$ higher than the value calculated using the laser profiling technique $(\overline{R C L}=1.038)$. The differences in the mentioned results are caused by the fact that the results obtained for the laser profiling technique were based on measurements of only two contour profiles within the single blasting round, while for the TLS technique, the obtained results 
were based on measurements of the contour surface of the entire blasting round. The density of measurement points located along the length of the contour profile or on the contour surface is also important. According to the laser profiling technique, a measurement interval of 35 $\mathrm{cm}$ was adopted for the studied niche (i.e., 1 measurement point per $35 \mathrm{~cm}$ length of planned contour profile). The laser scanning (TLS) measurements of the studied niche were characterized by an average density of measurement points of approximately 1 point per $1 \mathrm{~cm}^{2}$. Higher density of measurement points enables a more accurate modeling of the measured profile/surface. In case of TLS measurements, an influence of the uneven distribution of the measurement points over different parts of the measured surface should also be mentioned. Parts of the surface with higher density of measurement points will have a stronger impact on the $T C I_{s}^{R}$ value (especially on the $\overline{O_{d}^{s}}$ parameter). Therefore, when using TLS, as even as possible distribution of the measuring points over the entire measured surface should be ensured. This can be achieved by selecting appropriate measurement parameters, a correct position of the scanner in relation to the measured surface and, if necessary, by conducting measurements with several different stations.

\subsection{Contour quality of studied niche for laser profiling technique compared to other tunnels}

The average $T C I_{R}$ value for three blasting rounds of the studied niche, calculated using the laser profiling technique, is 71.730 . This means that the quality of the niche contour should be assessed as high. Only about $7 \%$ of all blasting rounds of Korean tunnels (i.e., Sujeongsan, Iyang, Namseon, and Kyeryong) studied in [1] were similar or higher. However, none of the blasting rounds of Norwegian tunnels (i.e., LS02, Marienborg) studied in [1] achieved this level. Several factors can influence this result. One of them is the similarity of the Polish and the Korean approach to the design of tunnels, according to which any overbreak is filled with shotcrete. This implies that tunnel engineers strive to achieve the highest possible contour quality. Another factor is a relatively small crosssectional area of the studied niche, i.e., approximately $21.30 \mathrm{~m}^{2}$, which, according to [1], is conducive to precise drilling of blast holes. For comparison, the smallest crosssectional area in all tunnels studied in [1] is approximately $45.50 \mathrm{~m}^{2}$ (Sujeongsan Tunnel). Unfortunately, it is not possible to compare the obtained results to those reported in [2] (i.e., for a road tunnel in the northern province of
Norway). Costamagna et al. [2] used different $\mathrm{C}_{1}$ and $\mathrm{C}_{2}$ factors to calculate the $\mathrm{TCI}_{\mathrm{R}}$. Thus, it is recommended to publish not only the TCI values but also the values of the $\mathrm{O}_{\mathrm{d}}$, RCL, and $\mathrm{V}_{\mathrm{o}}$ parameters, which will enable the comparison of the obtained results from different studies.

\subsection{Contour quality within sides and a roof for laser profiling and TLS techniques}

For the studied niche, the average value of the overbreak depth for both sides calculated according to laser profiling technique is $\overline{O_{d}}=10.171 \mathrm{~cm}$ (Fig. 12). For roofs, this value is $37.2 \%$ higher, i.e., $\overline{O_{d}}=13.952 \mathrm{~cm}$. According to the TLS technique, these values amount to $\overline{O_{d}^{s}}=9.767 \mathrm{~cm}$ for both sides and $\overline{O_{d}^{s}}=12.954 \mathrm{~cm}$ for roofs $(32.6 \%$ higher than the values for sides), respectively (Fig. 14). Therefore, regardless of the technique used, it can be concluded that for the studied niche, the average value of the overbreak depth within the roof is more than $30 \%$ higher than that within the sides. Regardless of the technique used, the average value of the contour roughness for the roofs is approximately 5\% higher than that for sides (Figs 13 and 15). The above results may be influenced by the dense network of rock fractures occurring in the Carpathian flysch [27] (a quality aspect of the rock mass), in particular, by the value of an angle between the dominant direction of the fractures and the planned contour surface. It should also be remembered that parts of the rock mass weakened (detached) by the explosion remain in their place, within the sides, while they fell off from the roof. The value of the overbreak depth for the roof located near the tunnel face is also influenced by the value of the angle between the direction of the fall of the rock layers and the direction of tunnel boring. The obtained results confirm the observations of Kim and Bruland [1] who reported that the TCI value is influenced by many factors, and in particular, the factors of quality of the rock mass and the shape of the tunnel.

\subsection{Using the $\mathrm{TCl}$ in the engineering practice}

On a basis of the RMR classification, the rock mass located around the studied niche was classified as class three rock mass, which is a high result for the Carpathian flysch. This corresponds to the so-called medium-strong rock mass. The total score for this class ranges from 41 to 60 points. The linear relationship proposed in [1]: $T C I_{R}=0.045 \cdot R M R+62.830$ was characterized by a very low value of $R^{2}=0.088$; therefore, it cannot be considered 


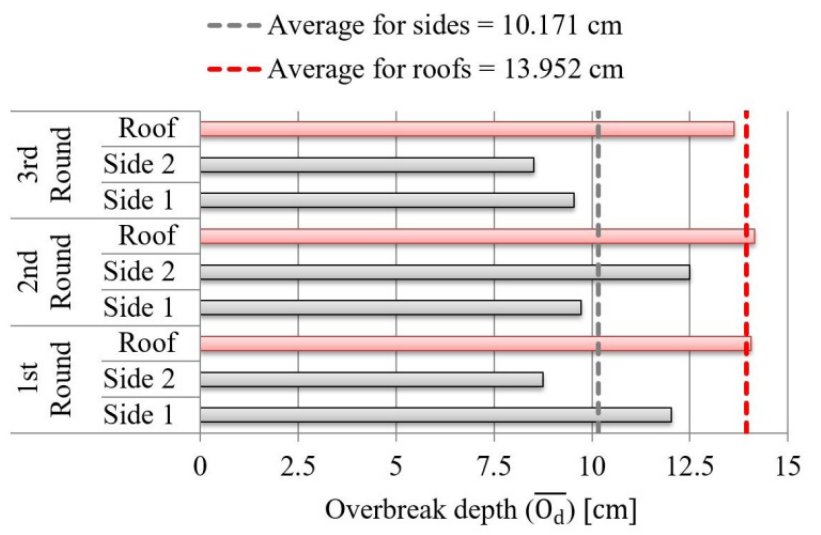

Figure 12: Values of the overbreak depth $\left(\overline{O_{d}}\right)$ for individual elements of each of the three blasting rounds.

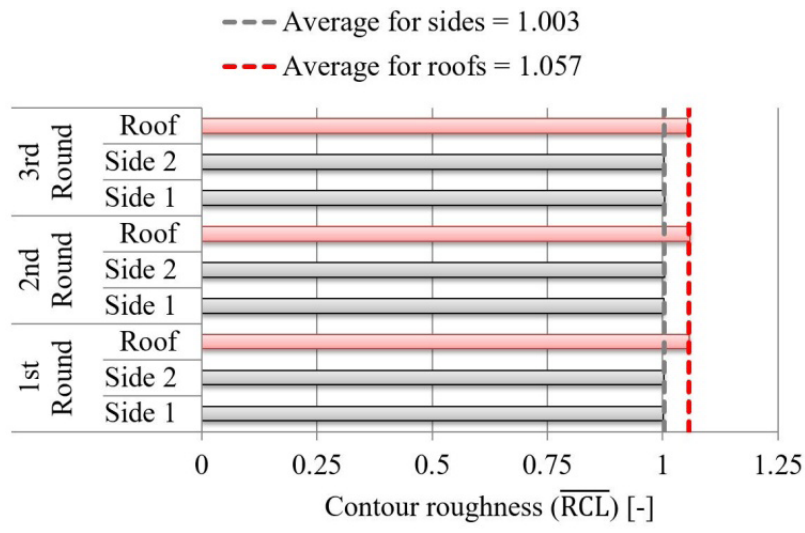

Figure 13: Values of the contour roughness $(\overline{R C L})$ for individual elements of each of the three blasting rounds.

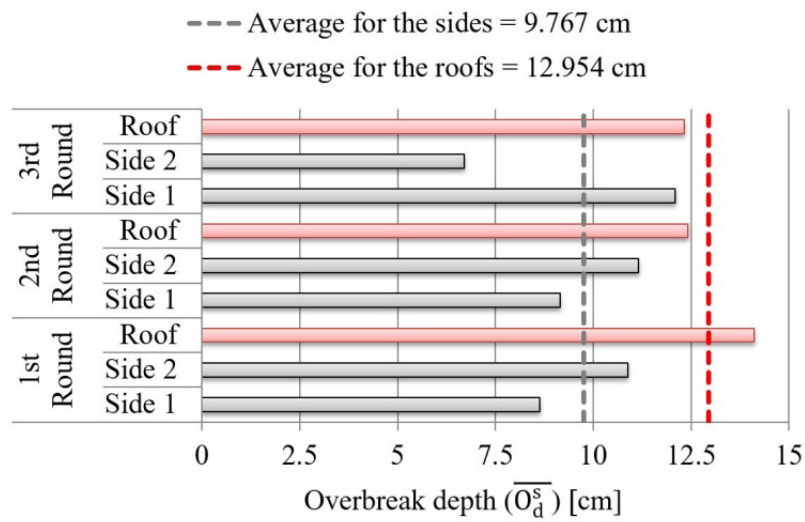

Figure 14: Values of the overbreak depth $\left(\overline{O_{d}^{s}}\right)$ for individual elements of each of the three blasting rounds.

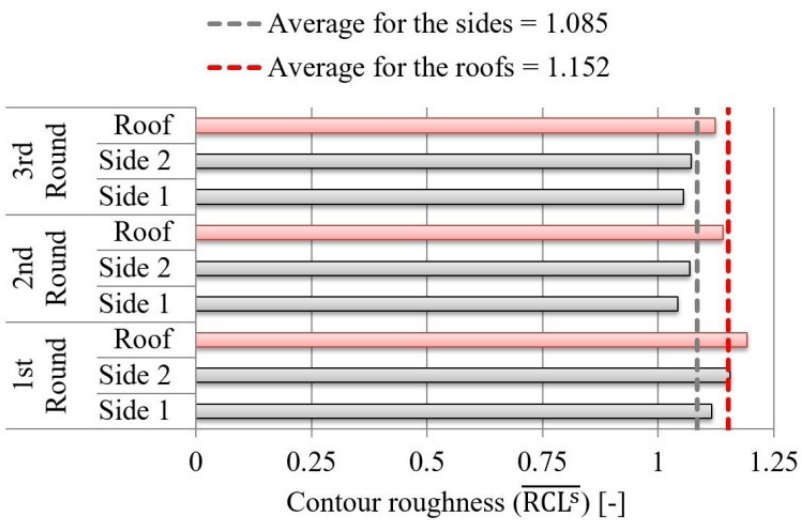

Figure 15: Values of the contour roughness $\left(\overline{R C L^{s}}\right)$ for individual elements of each of the three blasting rounds.

reliable. The relationship between TCI and RMR for the Carpathian flysch has not been specified in this article due to the small amount of data, but in the future, such a relationship will be the subject of more detailed studies, especially taking into account the analysis of individual parameters on the basis of which the RMR is determined.

Defining a more precise relationship between the quality of a rock mass (assessed according to, e.g., RMR) and the TCI value requires further studies in different geological conditions. It may be very difficult to establish such relationship; however, it will enable the tunnel engineers to conduct ongoing local monitoring of the quality of the rock mass using the TCI. It can also be assumed that there is a relationship between the TCI value and the parameters of contact between the tunnel lining and the surrounding rock. It appears that the aforementioned contact phenomenon is important for the safety of the structure [28]. Thus, apart from the economic aspect [29], the TCI can also potentially become a useful tool for evaluation of the geotechnical and safety aspects of the structure.

In addition to the rock mass quality, the tunnel shape, and the cross-sectional area, a number of other factors affect the TCI value. They include a location of blast holes, types and amounts of explosives used, and quality of blasting works [1]. Further comprehensive studies are needed to accurately assess the impact of abovementioned factors. The effectiveness of those studies will largely depend on the effective and accurate measurement of the contour surface geometry. Such measurements can be performed with the TLS technology. For this reason, the TLS technique presented in this paper is especially useful. 
- Meosured point cloud of single round

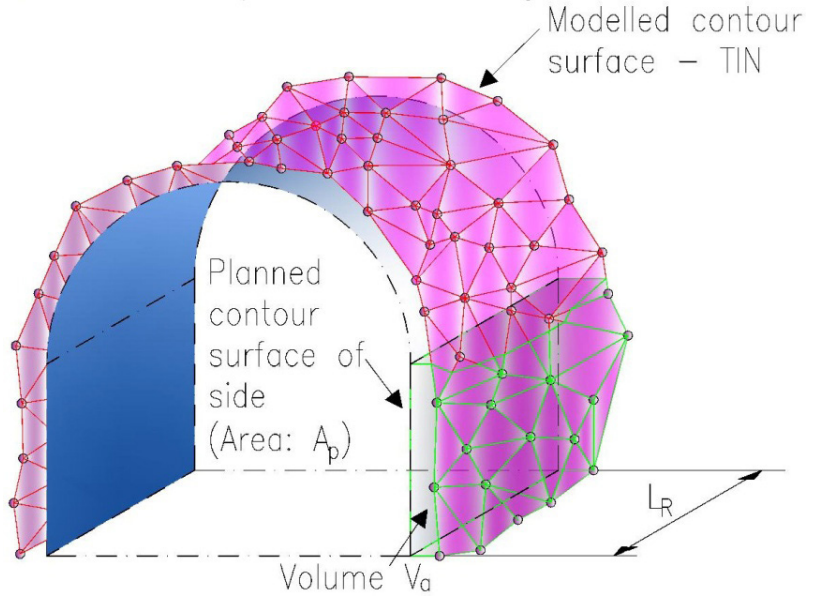

Figure 16: Planned and modeled (TIN) contour surfaces and volume $\mathrm{V}_{\mathrm{a}}$.

\subsection{Potential improvements in the TLS technique}

Although the TLS technique is based on a large amount of data (such as the measured point cloud), it cannot be considered optimal for calculating the overbreak depth parameter $\overline{O_{d}^{s}}(7)$. It does not take into account the spatial distribution of the measured points, but only their distance from the planned contour surface. For the sides, this can be remedied by defining the parameter $\overline{O_{d}^{s}}$ as the ratio of a volume between the modeled contour surface (TIN) and the planned contour surface $\left(V_{a}\right)$ to the area of the planned contour surface $\left(A_{p}\right)$ (Fig. 16):

$$
\overline{O_{d}^{s}}=\frac{V_{a}}{A_{p}}
$$

The calculation of the volume $V_{a}$, defined as above, is not problematic, as it can be done successfully in the AutoCAD Civil 3D software. Unfortunately, it is not possible for the roof. To determine the parameter $\overline{O_{d}^{s}}$ for the roof, the so-called F-operator [30] for the modeled contour surface (TIN) and the planned contour surface must be used. This operation consists in "erasing" the original shape of the surface. However, in this case, both the planned contour surface and the modeled contour surface (TIN) should be developed with the same radius of curvature, i.e., the radius of curvature of the planned contour surface (for the studied niche, this radius is $2.5 \mathrm{~m}$ ). Then, the value of the parameter $\overline{O_{d}^{s}}$ for the roof is equal to the ratio of the volume between the modeled contour surface (TIN) and the planned contour area (following the operation described above) $\left(V_{a}^{F}\right)$ to the area of the planned contour surface $\left(A_{p}\right)$ :

$$
\overline{O_{d}^{s}}=\frac{V_{a}^{F}}{A_{p}}
$$

According to the authors' knowledge, currently no software is available that allows the above-described operation to be performed for the TIN surface created on the basis of a point cloud. Therefore, it is planned to start works on development of a computational algorithm that would enable such operation in the future.

\section{Conclusions}

This article proposes the TLS technique for calculating the TCI with the effective use of TLS data. On the basis of the TLS measurements of the contour surface carried out in one of the niches of the "Mały Lubon'" tunnel, TCI values calculated in accordance with laser profiling and TLS techniques were compared. The primary conclusions can be summarized as follows:

- The TLS technology can be used to determine the TCI value in accordance with the methodology proposed by Kim and Bruland [1], when appropriate numerical surface modeling tools, e.g., TIN, are used.

- The TLS technique for calculating the TCI enables the effective use of large amounts of data from laser scanning, i.e., a point cloud. Compared to the evaluation of the TCI value on the basis of two profiles within a single blasting round, with the proposed technique it is possible to obtain more reliable results concerning the contour quality assessment of the entire blasting round surface.

- The probability that the modeled contour surface will be accurate increases with the number of measured points (provided that all points are distributed on the contour surface as evenly as possible). Therefore, when measuring with TLS, it should be ensured that the measurement parameters are selected correctly and the scanner is set in the proper position in relation to the measured surface and, if necessary, measurements should be performed from several different positions.

- The average value of the overbreak depth $\left(\mathrm{O}_{d}\right)$ within the roof is more than $30 \%$ higher than that within the sides. On the other hand, the average value of the contour roughness parameter (RCL) for the roof 
is approximately $5 \%$ higher than that for the sides. Therefore, it can be concluded that to effectively manage the quality of the entire contour surface, different actions are required depending on its individual parts.

- Conditions for TLS measurements in a tunnel can be unfavorable. Factors which should be taken into account include moisture of the measured surface, as well as a temperature, pressure, humidity, and airborne dust.

- The possibility of using the TLS measurement results for accurate modeling of the surface of the tunnel contour and, consequently, for determining the TCI value may be extremely important for determining a relationship between the TCI value and various factors (e.g., RMR). This option is offered by the TLS technique for evaluating the TCI presented in this paper.

- The TLS technology is still not widely available on tunneling sites, and such measurements require the involvement and considerable knowledge of a person who carries them out. Another significant obstacle is the difficulty of integrating it with the technological process of tunneling. However, taking into account benefits resulting from its use, it can be treated as very promising.

Acknowledgment: The authors thank the representatives of the general contractor of the "Mały Luboń" tunnel (i.e., ASTALDI) for enabling them to perform TLS measurements at that construction site.

\section{References}

[1] Kim, Y., \& Bruland, A. (2019). Analysis and evaluation of tunnel contour quality index. Automation in Construction, 99, 223-237.

[2] Costamagna, E., Oggeri, C., Segarra, P., Castedo, R., \& Navarro, J. (2018). Assessment of contour profile quality in D\&B tunnelling. Tunnelling and Underground Space Technology, 75, 67-80.

[3] Soilán, M., Sánchez-Rodríguez, A., del Río-Barral, P., PerezCollazo, C., Arias, P., \& Riveiro, B. (2019). Review of laser scanning technologies and their applications for road and railway infrastructure monitoring. Infrastructures, 4(4), 58.

[4] Zogg, H. M., \& Ingensand, H. (2008). Terrestrial laser scanning for deformation monitoring: Load tests on the Felsenau Viaduct (CH). International Archives of the Photogrammetry, Remote Sensing and Spatial Information Sciences, 37(B5), 555-562.

[5] Xu, H., Li, H., Yang, X., Qi, S., \& Zhou, J. (2019). Integration of terrestrial laser scanning and nurbs modeling for the deformation monitoring of an earth-rock dam. Sensors, 19(1), 22.
[6] Lenda, G., Siwiec, J., \& Kudrys, J. (2020). Multi-Variant TLS and SfM Photogrammetric Measurements Affected by Different Factors for Determining the Surface Shape of a Thin-Walled Dome. Sensors, 20(24), 7095.

[7] Brazeal, R. (2013). Low cost spherical registration targets for terrestrial laser scanning. SUR 6905-point cloud analysis.

[8] Bazarnik, M. (2014). The potential of terrestrial 3D laser scanning in inventory and monitoring of tunnel railway (in Polish). Zeszyty Naukowo-Techniczne Stowarzyszenia Inżynierów i Techników Komunikacji w Krakowie. Seria: Materiały Konferencyjne.

[9] Suchocki, C., Damięcka-Suchocka, M., \& Katzer, J. 5. Influence of factors on the value of the reflection strength of a laser beam in terrestrial laser scanning (in Polish).

[10] Lemmens, M. (2011). Terrestrial laser scanning. In Geoinformation (pp. 101-121). Springer, Dordrecht.

[11] Remondino, F. (2003). From point cloud to surface: the modeling and visualization problem. International Archives of the Photogrammetry, Remote Sensing and Spatial Information Sciences, 34.

[12] Sanchez, T., Conciatori, D., Ben-Ftima, M., \& Massicotte, B. (2020). Terrestrial laser scanning for structural inspection with Kriging interpolation. Structure and Infrastructure Engineering, 1-10.

[13] Wang, W., Zhao, W., Huang, L., Vimarlund, V., \& Wang, Z. (2014). Applications of terrestrial laser scanning for tunnels: a review. Journal of Traffic and Transportation Engineering (English Edition), 1(5), 325-337.

[14] Xie, X., \& Lu, X. (2017). Development of a 3D modeling algorithm for tunnel deformation monitoring based on terrestrial laser scanning. Underground Space, 2(1), 16-29.

[15] Yang, Q., Zhang, Z., Liu, X., \& Ma, S. (2017). Development of laser scanner for full cross-sectional deformation monitoring of underground gateroads. Sensors, 17(6), 1311.

[16] Cheng, Y. J., Qiu, W., \& Lei, J. (2016). Automatic extraction of tunnel lining cross-sections from terrestrial laser scanning point clouds. Sensors, 16(10), 1648.

[17] Han, S., Cho, H., Kim, S., Jung, J., \& Heo, J. (2013). Automated and efficient method for extraction of tunnel cross sections using terrestrial laser scanned data. Journal of computing in civil engineering, 27(3), 274-281.

[18] Barla, G., Antolini, F., \& Gigli, G. (2016). 3D Laser scanner and thermography for tunnel discontinuity mapping. Geomechanics and Tunnelling, 9(1), 29-36.

[19] Tan, K., Cheng, X., Ju, Q., \& Wu, S. (2016). Correction of mobile TLS intensity data for water leakage spots detection in metro tunnels. IEEE geoscience and remote sensing letters, 13(11), 1711-1715.

[20] Živec, T., Anžur, A., \& Verbovšek, T. (2019). Determination of rock type and moisture content in flysch using TLS intensity in the Elerji quarry (south-west Slovenia). Bulletin of Engineering Geology and the Environment, 78(3), 1631-1643.

[21] Pejić, M. (2013). Design and optimisation of laser scanning for tunnels geometry inspection. Tunnelling and underground space technology, 37, 199-206.

[22] Thiel, K. (1995). Physico-mechanical properties and models of rock massifs of the Polish flysch Carpathians (in Polish). IBW PAN Gdańsk, Biblioteka Naukowa Hydrotechnika, (19).

[23] Faro Focus Laser Scanners, (2021), FARO,https://www.faro. com/en/Products/Hardware/Focus-Laser-Scanners 
[24] SCENE User Manual, (2020), FARO, https://faro.app.box. com/s/uivkgf3jyrxcxn5ofazlohjnadddknhr/file/730718082810

[25] ReCap Support and learning, (2021), Autodesk, https:// knowledge.autodesk.com/support/recap/learn?fbclid= IwAROtmnHo5wFwwVauarBL_dUZruBnsjZOvlbQDVoqFL_ fry5QfqgAU71jvPw

[26] AutoCAD Civil 3D 2010 User's Guide, (2009), Autodesk, http://images.autodesk.com/adsk/files/civil3d_ ug.pdf?fbclid=IwAR1k-Im5CB61VP7GpvuNbWZh3Fumhd9ndLgQ FSTHYmwAuonzNUIdAz67Lls

[27] Niedbalski, Z., Matkowski, P., \& Majcherczyk, T. (2018). Application of the NATM method in the road tunneling works in difficult geological conditions-The Carpathian flysch. Tunnelling and Underground Space Technology, 74, 41-59.

[28] Ye, Z., \& Zhang, C. (2020). Influence of Loose Contact between Tunnel Lining and Surrounding Rock on the Safety of the Tunnel Structure. Symmetry, 12(10), 1733.

[29] Kim, Y., \& Bruland, A. (2015). A study on the establishment of Tunnel Contour Quality Index considering construction cost. Tunnelling and Underground Space Technology, 50, 218225.

[30] Geometrical product specifications (GPS) - Surface texture: Areal - Part 2: Terms, definitions and surface texture parameters (ISO 25178-2:2012) 